\title{
A Cost-Benefit Analysis of Two Alternative Models of Maternity Care in Ireland
}

\author{
Christopher G. Fawsitt ${ }^{1,2,3}$ (D) Jane Bourke ${ }^{2} \cdot$ Aileen Murphy $^{2} \cdot$ Brendan McElroy $^{2}$ • \\ Jennifer E. Lutomski ${ }^{4} \cdot$ Rosemary Murphy $^{2} \cdot$ Richard A. Greene $^{3}$
}

Published online: 21 August 2017

(C) The Author(s) 2017. This article is an open access publication

\begin{abstract}
Background The Irish government has committed to expand midwifery-led care alongside consultant-led care nationally, although very little is known about the potential net benefits of this reconfiguration.

Objectives To formally compare the costs and benefits of the major models of care in Ireland, with a view to informing priority setting using the contingent valuation technique and cost-benefit analysis.

Methods A marginal payment scale willingness-to-pay question was adopted from an ex ante perspective. 450 pregnant women were invited to participate in the study. Cost estimates were collected primarily, describing the average cost of a package of care. Net benefit estimates were calculated over a 1-year cycle using a third-party payer perspective.

Results To avoid midwifery-led care, women were willing to pay €821.13 (95\% CI 761.66-1150.41); to avoid consultantled care, women were willing to pay $€ 795.06$ (95\% CI
\end{abstract}

Electronic supplementary material The online version of this article (doi:10.1007/s40258-017-0344-8) contains supplementary material, which is available to authorized users.

Christopher G. Fawsitt

c.fawsitt@bristol.ac.uk

1 Health Economics at Bristol (HEB), Bristol Medical School, University of Bristol, Canynge Hall, 39 Whatley Road, Bristol BS8 2PS, UK

2 Department of Economics, Cork University Business School, University College Cork, Cork, Ireland

3 National Perinatal Epidemiology Centre, University College Cork, Cork, Ireland

4 Radboud Institute for Health Sciences, Radboud University Medical Center, Nijmegen, The Netherlands
695.51-921.15). The average cost of a package of consultantand midwifery-led care was $€ 1,762.12 \quad(95 \% \quad \mathrm{CI}$ 1496.73-2027.51) and €1018.47 (95\% CI 916.61-1120.33), respectively. Midwifery-led care ranked as the best use of resources, generating a net benefit of $€ 1491.22$ (95\% CI 989.35-1991.93), compared with $€ 123.23$ (95\% CI - 376.58 to 621.42) for consultant-led care.

Conclusions While both models of care are cost-beneficial, the decision to provide both alternatives may be constrained by resource issues. If only one alternative can be implemented then midwifery-led care should be undertaken for low-risk women, leaving consultant-led care for high-risk women. However, pursuing one alternative contradicts a key objective of government policy, which seeks to improve maternal choice. Ideally, multiple alternatives should be pursued.

\section{Key points for decision-makers}

In Ireland, the government has pledged to improve maternal choice by expanding midwifery-led care throughout the country.

This is the first study to estimate the net benefit of consultant- and midwifery-led models of care using cost-benefit methodology and women's preferences for maternity care, with the results arriving at a particularly useful juncture in Irish policy formulation.

Whether midwifery-led care should be developed in Ireland depends on resource constraints, although the model of care is consistently ranked as the best use of public resources when compared with consultantled care. 


\section{Introduction}

With falling perinatal statistics and maternal mortality rates in many developed countries, the configuration of maternity care has advanced in recent years to afford consumers greater choice on a range of maternity care services. In the UK, the National Institute for Health and Care Excellence (NICE) has moved to ensure women are provided with a range of maternity care options at hospital level, while also ensuring prospective mothers are free to choose homebased care [1]. At hospital level, women may choose between two broad models of care: consultant-led care and midwifery-led care. Consultant-led care is provided in an obstetric unit, or consultant-led unit (CLU), and a team of midwives and obstetric doctors are responsible for providing maternity care. In a CLU, the full range of medical services, including obstetric, anaesthetic and neonatal care, is immediately available. Midwifery-led care, on the other hand, is delivered in a midwifery-led unit (MLU) by a team of midwives and no obstetric doctors or medical services are immediately available, although these services can be accessed in an adjoined CLU in the event of an obstetric complication or emergency. Internationally, midwifery-led care has been found to be associated with fewer interventions and comparable adverse outcomes when compared with consultant-led care [2-6]. Women also report higher satisfaction levels following care in a MLU [3, 7].

Despite these findings, the service remains sparsely provided in some countries. In Ireland, for example, maternity care is largely consultant-driven, with 19 out of 21 maternity units comprising CLUs and the remaining two units comprising MLUs. The two MLUs are located in the north east of the country and cater to small geographic populations [8]. In an effort to improve maternal choice and potentially reduce costs, while still maintaining high quality obstetric care, the Irish government recently pledged to expand midwifery-led care throughout the country [9]. However, there is little evidence to suggest women would utilise this service and, given limited healthcare resources, there needs to be an increased focus on priority setting where the allocation of resources reflects consumers' preferences and value for money.

Increasingly, economic evaluation studies are being published to guide decision-making on the efficient use of public resources. The National Health Service (NHS) in the UK relies on cost-effectiveness analyses (CEAs) to inform resource allocation. However, with respect to priority setting, cost-benefit analysis (CBA) offers a number of key advantages over other methodologies [10]. The approach is consistent with welfare economics, which seeks to provide an explicit ranking of available alternatives in terms of their derived benefits and expected costs [11]. Under resource constraints, this ranking of alternatives provides information on the most desirable use of resources. In addition, the common unit of analysis facilitates comparisons between different dimensions of health and healthcare, which can be extended to other sectors [10].

The contingent valuation method (CVM), or willingness to pay (WTP) technique, is commonly used to elicit monetary valuations of health and healthcare [12], among other areas [13], and is regarded as a valid and reliable tool for benefit valuations [14] as it directly estimates the Hicksian welfare measure of CBA [15]. Haefeli et al. [16] demonstrated its feasibility in valuing spinal interventions for use in CBA. However, there remains some debate around the appropriate use of values in CBA [17]. The decision to elicit patient values or general population values is a normative issue [18]. Since CBA is underpinned by welfare theory, which is concerned with the social ranking of alternatives, the natural perspective is a societal perspective; hence, general population values may be more relevant than patient values [19]. Although Shackley and Donaldson [17] recommend eliciting patient values when the specific service is publicly funded as patients bear the opportunity cost of any related decision, the question is how these values should be elicited.

In the context of priority setting, the marginal approach to the WTP question provides a useful elicitation technique as it provides an explicit ranking of alternative uses of resources $[17,20]$. The marginal approach asks respondents to indicate their maximum (or minimum) WTP (willingness to accept (WTA)) for their preferred over their less preferred alternative. This scenario description is important from a policy perspective as it ranks resources and supports the use of patient values to elicit WTP when the good or service is publicly funded [17]; if only one alternative can be implemented then patients bear the direct opportunity cost of the public policy decision. Patients are also often the best judge of their own welfare and most adept to infer valuations about the burden of the health state under consideration. Whether an alternative should be implemented then depends on the relative strength of patients' preferences, relative costs, and the budget constraint [17].

In this paper, we apply the marginal approach to investigate the costs and benefits of the two major models of maternity care in Ireland, consultant- and midwifery-led care, with a view to informing priority setting. We examine patient preferences from an ex ante perspective and collect costs using micro- and grosscosting techniques. The perspective assumed is that of the Irish healthcare payer. 


\section{Data and Methods}

\subsection{Sourcing Benefits}

A payment scale design was adopted to assign a monetary valuation to a package of care in a CLU or MLU, which covers antenatal, intrapartum and postnatal care. We used the payment scale question as it is favoured in the health economics literature [21]. User values were sourced; pregnant women are considered the best judge of their welfare and are directly affected by the opportunity cost of any public policy decision regarding maternity care in Ireland. In the CVM, women were presented with a hypothetical scenario and asked to choose between consultant- and midwifery-led care, and to indicate how much they would be willing to give up to receive their preferred over their less preferred model of care, referred to as the 'marginal approach' [20]. Twelve interval points were used in the payment scale question, which ascended in units of $€ 100$ from $€ 100$ to $€ 800$, then $€ 200$ to $€ 1000$, and $€ 250$ thereafter. Women were asked to express their maximum WTP if it was not listed. A 'zero' bid was not included to minimise the potential for protest responses (Fig. 1). Since care in a MLU is distinctly different to care in a CLU, the scenarios were described using specific attributes. The attributes included continuity of care, average waiting time at each antenatal visit, and access to obstetric, anaesthetic and neonatal care. These attributes derived from qualitative research, which is described elsewhere [22]. The attributes described the 'typical' scenario found in a CLU and MLU. An out-of-pocket expense, or co-payment, was employed as the payment vehicle given women's familiarity with out-of-pocket expenses for maternity care. In Ireland, women may opt for private care which entitles them to antenatal and intrapartum care being provided by an obstetric doctor. A private package of care costs approximately $€ 3,500$ (based on expert opinions from consultant obstetricians; data unpublished). This provided a useful 'benchmark' for women to value public care against, which would not be possible with other payment vehicles. The direction of payment assumed was WTP. Respondents were asked to indicate how much they would be willing to give up for the welfare gain associated with their preferred maternity care package. The exact welfare measure used to investigate WTP was compensating variation (CV). This is the amount of money that is required to keep utility levels constant [19]. The WTP question was described prior to the event occurring where women were at the point of consuming maternity care, referred to as an ex ante perspective. The estimates were considered valid if they did not exceed the price of a package of private care, which represents a superior level of care that women decidedly declined by choosing publicly-provided maternity care.
Pilot testing was undertaken to assess the properties of the contingent valuation study. Reassuringly, the WTP values elicited during the pilot studies were similar and comparable with results obtained during qualitative research. The final survey was distributed across five maternity units in Ireland during 2014 [23]. 450 surveys in booklet form, along with an invitation letter, information leaflet, pre-paid return envelope and a consent form, were distributed to pregnant women during antenatal care. Three reminders were distributed to participants who neither returned the survey nor opted out of the study over the course of 8 weeks. Only women who were considered to be at low risk of obstetric complications were invited to participate in the study since high-risk women typically require interventions that are not available in MLUs. Low risk was defined according to the NICE guidelines and includes women between 18 and 39 years of age with no history of obstetric complications or Caesarean section and no contraindications of morbidities at the time of pregnancy [1].

Ethical approval for this study was granted by the Clinical Research Ethics Committee, Division of Obstetrics and Gynaecology in Cork University Maternity Hospital; the Health Service Executive (HSE) Mid-Western Regional Hospital Research Ethics Committee; the HSE SouthEastern Regional Hospital Research Ethics Committee; and the Research Ethics Committee in the National Maternity Hospital, Dublin.

Range bias is often associated with payment scale WTP questions [19]. It suggests respondents may be influenced to choose a monetary value from within the range of values listed in the payment scale. To assess this bias, we conducted an open-ended WTP question, which is not subject to range bias, and compared responses from both surveys. Answers elicited from the open-ended WTP question were not statistically different from the payment scale WTP question. For simplicity, we only report the WTP responses from the payment scale question below; results from the open-ended WTP question are provided in the Electronic Supplementary Material (ESM), Table S1.

\subsection{Sourcing Costs}

Cost estimates are derived from primary and secondary data collection, and describe the average cost of a package of care in a CLU and MLU, which covers antenatal, intrapartum and postnatal care. All costs accruing to the Health Service Executive (HSE) (third-party payer) were included in this analysis. The HSE is responsible for the management and delivery of public health services in Ireland. Resources were valued at their opportunity costs, which were reflected in current market prices [24]. Microcosting and gross-costing techniques were employed to 
In the following question we would like to ask you how much you would value care in an obstetric unit or a midwifery-led unit. Please try to provide an answer, even if it is difficult. Please note that maternity care is free and will remain free. What we are trying to find out is how much value you would place on care in an obstetric unit or care in a midwifery-led unit, depending on your preferred location of care.

One way to find out how much value you place on maternity care is to ask you how much of your own money you would be willing to give up to receive a maternity care package in your preferred location. The following describes two locations and packages of care, please read them carefully before answering the following two questions.

Obstetric unit: a clinical location in which care is provided by a team of midwives and doctors, both during antenatal care and care during labour. Antenatal care is typically provided by a team of midwives and doctors and you could meet either one at each visit, waiting an average of two hours each time. You are not guaranteed the same carer for the duration of your antenatal care and care during labour. During labour, midwives take primary responsibility for your care, but doctors and all medical services including obstetric, neonatal and anaesthetic care are available on site should they be needed.

Alongside midwifery-led unit: a clinical location in which care is provided solely by midwives, both during antenatal care and care during labour. Antenatal care is typically provided by the same midwife, where you can wait an average of 10-20 minutes at each visit. You could be guaranteed the same carer from antenatal care to care during labour. The full range of medical services, including obstetric, neonatal and anaesthetic care, is available, should they be needed, in the same building.

1. In which location would you prefer to receive your entire maternity care? (Please tick one Box)

Obstetric unit

(Alongside) Midwifery-led unit .

2. Based on your choice above, what is the maximum amount you would be willing to pay to receive your entire maternity care in your preferred maternity unit instead of your less preferred maternity unit? The following lists several amounts of money, please circle the maximum amount you would be willing to pay. If the maximum amount is not listed, please write in the exact amount in the space provided.

$\begin{array}{cccc}€ 100 & € 200 & € 300 & € 400 \\ € 500 & € 600 & € 700 & € 800 \\ € 1,000 & € 1,250 & € 1,500 & €\end{array}$

Fig. 1 Sample willingness-to-pay question presented to women

estimate the average cost of care per woman. All unit costs were valued at 2016 prices and expressed in Euro $(€)$.

A resource use inventory was developed for this study. The inventory identified all staff inputs during an uncomplicated pregnancy and delivery, among other resource use inputs. The inputs derived from available literature and expert opinions of consultant obstetricians at a teaching hospital, who reviewed and agreed upon the inventory. Resource use information on the obstetric path of women availing of consultant- and midwifery-led care was obtained from the MidU [8] study, which evaluated the effectiveness and cost-effectiveness of consultant- and midwifery-led care in Ireland in 2005 and 2006 using a randomised controlled trial (RCT) and CEA. Information on antenatal visits, ultrasound scans, antepartum cardiotocographs, biophysical profiles, labour duration and number of home visits following hospital discharge were obtained from the RCT component of the MidU [8] study. As these data were 10 years old, expert opinion was sought to ensure the inventory reflected current medical practices. The resource use inventory is provided in the ESM in Table S2. 
An estimate of postnatal length of stay was sought as variations in time spent in hospital were expected across these models of care. According to the Hospital In-patient Enquiry (HIPE) Scheme, the average postnatal length of stay following an uncomplicated childbirth in a CLU is 2.6 days [25]. However, this estimate is based on both public and private patients, which may overestimate the average postnatal length of stay for public patients. HIPE data, sourced from a teaching hospital for an uncomplicated childbirth for public patients, reported an average postnatal length of stay of 2.1 days for 2014 (unpublished). This estimate was adopted in this analysis. The optimum average length of stay in a MLU is $24 \mathrm{~h}$ as follow-up home visits are provided for women availing of this model of care [8]. This corresponds with the average length of stay in the UK where a recent study found that women stayed in hospital for $25.7 \mathrm{~h}$ after giving birth in a MLU $(\mathrm{SD}=20.3)$ [26]. Given the lack of information on the average length of stay in a MLU in Ireland, this UK estimate was included in this analysis.

In terms of medical consumables and pharmaceuticals, many of these costs were excluded as the level of resource use was similar across both arms [8]. While certain variation exists between both models of care, such as in the use of transcutaneous electrical nerve stimulation (TENS), it can be reasonably assumed that these costs are negligible.
The resource use inventory was valued according to administrative costs and length of stay costs. Staff costs for midwives, public health nurses and medical doctors were obtained from consolidated salary scales [27], and adjusted for pay-related costs in accordance with recent guidelines [28], as illustrated in Table S3 (ESM). Length of stay was valued according to costs per bed-day. Costs per bed-day are informed by the Ready Reckoner of Inpatient and Daycase Activity and Costs, or Diagnostic Related Groups (DRGs) [29]. The relevant DRG (O60Z) describes a cost per bed-day following an uncomplicated vaginal delivery. The estimated cost per bed-day was $€ 2,316$ for 2.6 days postnatal stay. This was deemed considerably high for what is regarded as a recuperative period in hospital, requiring minimal resource use [8]. The Ready Reckoner estimates that a cost-per bed-day exceeding 2.6 days is €687 [29]. This estimate was considered a better representation of the cost per bed-day following a natural birth, and was adopted in this analysis.

We were concerned with estimating costs that may be generalizable to any maternity unit in Ireland. As a consequence, capital costs were excluded from this analysis. The study focused on utilising existing infrastructure to establish a MLU, rather than building a MLU. This may involve converting another building within the hospital into a MLU, or maximising existing infrastructure by dedicating a wing or section of a CLU to midwifery-led care.

Table 1 Breakdown of costs by normal birth

\begin{tabular}{|c|c|c|c|c|c|c|c|c|}
\hline \multirow[t]{3}{*}{ Resource use description } & \multicolumn{4}{|l|}{ MLU } & \multicolumn{4}{|l|}{ CLU } \\
\hline & \multirow{2}{*}{$\begin{array}{l}\text { Mean } \\
\text { cost }\end{array}$} & \multirow{2}{*}{$\begin{array}{l}\text { Std. } \\
\text { error }\end{array}$} & \multicolumn{2}{|l|}{$95 \% \mathrm{CI}$} & \multirow{2}{*}{$\begin{array}{l}\text { Mean } \\
\text { cost }\end{array}$} & \multirow{2}{*}{$\begin{array}{l}\text { Std. } \\
\text { error }\end{array}$} & \multicolumn{2}{|l|}{$95 \% \mathrm{CI}$} \\
\hline & & & Lower & Upper & & & Lower & Upper \\
\hline Antenatal visit to MLU & $€ 53.69^{\mathrm{a}}$ & $€ 1.65$ & $€ 52.04$ & $€ 55.33$ & - & - & - & - \\
\hline Antenatal visit to CLU & $€ 7.86^{\mathrm{b}}$ & $€ 1.30$ & $€ 6.57$ & $€ 9.16$ & $€ 120.30$ & $€ 7.52$ & $€ 112.78$ & $€ 127.83$ \\
\hline Consultant role in overseeing antenatal visit & $€ 4.41^{\mathrm{c}}$ & $€ 0.73$ & $€ 3.68$ & $€ 5.13$ & $€ 67.41$ & $€ 4.21$ & $€ 63.20$ & $€ 71.63$ \\
\hline Labour length & $€ 154.63$ & $€ 13.83$ & $€ 140.80$ & $€ 168.46$ & $€ 96.24$ & $€ 10.06$ & $€ 86.18$ & $€ 106.30$ \\
\hline Postnatal length of stay ${ }^{\mathrm{e}}$ & $€ 735.09$ & $€ 76.99$ & $€ 658.10$ & $€ 812.08$ & $€ 1442.70$ & $€ 238.97^{\mathrm{f}}$ & $€ 1203.73$ & $€ 1681.67$ \\
\hline Midwife home visits after birth in MLU & $€ 90.72$ & $€ 5.86$ & $€ 84.86$ & $€ 96.58$ & - & - & - & - \\
\hline $\begin{array}{l}\text { Average saving in visits by public health nurse as a } \\
\text { result of midwife's visits }\end{array}$ & $€-44.47^{\mathrm{d}}$ & - & - & - & - & - & - & - \\
\hline No. of ultrasound scans & $€ 13.95$ & $€ 0.76$ & $€ 13.19$ & $€ 14.70$ & $€ 22.92$ & $€ 2.78$ & $€ 20.14$ & $€ 25.71$ \\
\hline No. of antepartum cardiotocographs & $€ 2.60$ & $€ 0.76$ & $€ 1.84$ & $€ 3.35$ & $€ 12.11$ & $€ 1.41$ & $€ 10.70$ & $€ 13.52$ \\
\hline No. of biophysical profiles & - & - & - & - & $€ 0.43$ & $€ 0.43$ & $€ 0.00$ & $€ 0.87$ \\
\hline Total cost of normal birth & $€ 1,018.47$ & $€ 101.86$ & $€ 916.61$ & $€ 1120.33$ & $€ 1762.12$ & $€ 265.39$ & $€ 1496.73$ & $€ 2027.51$ \\
\hline
\end{tabular}

$M L U$ midwifery-led unit, $C L U$ consultant-led unit, Std. error standard error

a Hourly unit cost of a midwife is $€ 32.44$

${ }^{\mathrm{b}}$ Hourly unit cost of a registrar is $€ 46.19$

c Hourly unit cost of a consultant is $€ 141.52$

${ }^{\mathrm{d}}$ Hourly unit cost of a public health nurse is $€ 44.77$

e Cost per bed-day estimated at $€ 687$ per day, based on ready reckoner of inpatient and daycase activity and costs [26]

${ }^{\mathrm{f}}$ Estimated standard error is based on assumed standard deviation of 2 days 
Therefore, the capital cost of building a new MLU was excluded from this analysis. While these costs were excluded, the impact was assumed minimal as the equivalent annual cost was marginal. For instance, the MidU [8] study calculated a capital cost in the region of $€ 39.75$ per woman.

The cost estimates are presented in Table 1 . The average cost of care in a CLU was considerably higher than a MLU. The mean cost of a package of care in a MLU was $€ 1018.47$. The same package of care in a CLU costs $€ 1762.12$. This represented a cost differential of $€ 743.65$ in favour of a MLU.

\subsection{Cost-Benefit Analysis: Study Design and Methods}

The CBA compared the mean cost against the mean benefit of a package of care for a low-risk woman in Ireland. The estimated costs were assumed to represent the expected costs accruing to any maternity unit in Ireland, and estimated benefits to reflect the expected welfare gain of any low-risk woman availing of their preferred model of care. The time horizon for the study was 1 year. This allowed for an estimation of all costs and benefits arising during antenatal, intrapartum and postnatal care.

As the marginal approach was assumed to elicit monetary valuations of consultant- and midwifery-led care, cost estimates were calculated accordingly. In the base-case analysis, net benefit estimates were calculated using mean and median WTP valuations. While mean values are typically used within a policy context, median WTP values may be better predictors when the data are positively skewed [30]. Probabilistic sensitivity analysis (PSA) was performed to assess the robustness of the net benefit results to changes in key parameters. PSA is generally used within decision analytic models, although its application is suited when potential uncertainty in the input parameters exists. We assumed a normal distribution for costs and, instead of propagating the uncertainty in the overall cost of care in a MLU and CLU, we propagated the uncertainty in each of the input parameters informing the cost estimates, such as antenatal visits, duration of labour and postnatal length of stay, among other inputs. A normal distribution was assumed for the welfare estimates also. To reflect parameter uncertainty, 10,000 Monte Carlo simulations were performed using Microsoft Excel software [31]. We reported the net benefit results for the full WTP sample, as well as first-time mothers for whom the WTP question was truly ex ante. If the government decided to invest in MLUs and disinvest in CLUs, previous obstetric experience could be considered an invalid confounder of a woman's nominated WTP. By focusing only on first-time mothers, we could better represent the decision problem.

\section{Results}

\subsection{Willingness to Pay}

Questionnaires and signed consent forms were returned from 176 respondents, yielding a response rate of $39.1 \%$. Overall, 15 women were excluded due to the high-risk nature of their pregnancy: two women were excluded due to advanced maternal age and 13 were excluded due to a history of Caesarean section. There were 161 women in the final sample, as described in Table 2.

Five protest responses were obtained; among the responses, an unwillingness to pay for publicly provided maternity care was cited by women. 165 positive WTP responses were obtained and analysed in Stata 12 [32]. Preferences were distributed across consultant and midwifery-led care; 71 participants provided a positive WTP value in favour of care in a CLU, and 82 respondents provided a positive WTP value in favour of a MLU. The distribution of the WTP data was explored and the data were trimmed to remove potentially dubious responses. A $1 \%$ trim was applied at the upper end of the WTP

Table 2 Demographic characteristics for the contingent valuation method (CVM) sample

\begin{tabular}{ll}
\hline Variable & $N(\%)$ \\
\hline Age in years, mean (SD) & $30.9(4.3)$ \\
First baby (\%) & $73(45.3)$ \\
Number of children, mean (SD) & $1.7(0.85)$ \\
Marital status (\%) & \\
Single & $21(13.1)$ \\
Married & $107(66.8)$ \\
Cohabitating & $31(19.3)$ \\
Separated & $1(0.6)$ \\
Education status $(\%)$ & \\
Some primary/primary/junior & $7(4.3)$ \\
Leaving certificate & $23(14.3)$ \\
Diploma & $49(30.4)$ \\
Primary degree & $31(19.3)$ \\
Higher degree & $51(31.7)$ \\
Private health insurance $(\%)$ & \\
Yes & $89(55.3)$ \\
No & $72(44.7)$ \\
Household income $(\%)$ & \\
$<€ 834$ per month & $3(1.9)$ \\
$€ 834-€ 1,667$ per month & $16(10.2)$ \\
$€ 1668-€ 2500$ per month & $36(22.9)$ \\
$€ 2501-€ 3333$ per month & $33(21.0)$ \\
$€ 3334-€ 4167$ per month & $29(18.5)$ \\
Observations 167 per month & $40(25.5)$ \\
\hline
\end{tabular}


Table 3 Benefit estimates (compensating variation of WTP)

\begin{tabular}{lllllll}
\hline & Mean & Median & SD & Std. Error & \multicolumn{2}{l}{$95 \%$ CI } \\
\cline { 5 - 6 } & & & & 0.025 & 0.975 \\
\hline CLU & $€ 821.13$ & $€ 800.00$ & $€ 485.41$ & $€ 57.61$ & $€ 761.66$ & $€ 1,150.41$ \\
MLU & $€ 795.06$ & $€ 700.00$ & $€ 504.15$ & $€ 56.02$ & $€ 695.51$ & $€ 921.15$ \\
\hline
\end{tabular}

$C L U$ consultant-led unit, $M L U$ midwifery-led unit, WTP willingness to pay, $S D$ standard deviation, $S t d$. error standard error, $C I$ confidence interval distribution [33], resulting in the removal of one response. The WTP data are presented in Table 3. Women were willing to pay similar levels for both models of care. To avoid care in a MLU, women were willing to pay $€ 821.13$ (95\% CI 761.66-1150.41). For the welfare gain associated with care in a MLU instead of care in a CLU, women were willing to pay €795.06 (95 CI 695.51-921.15).

\subsection{Cost-Benefit Analysis}

Table 4 presents the results of the base case analysis. As illustrated above, women were willing to pay similar amounts for consultant-led care and midwifery-led care. To avoid care in a MLU, women were willing to pay $€ 821.13$, while to avoid care in a CLU, women were willing to pay $€ 795.06$. The mean cost of a package of care in a CLU was $€ 1762.12$, which was considerably higher than the same package of care in a MLU, estimated at $€ 1018.47$. The net benefit results therefore suggest that both models of care were cost-beneficial provided women received their preferred over their less preferred model of care. Despite the increased marginal cost of consultant-led care over midwifery-led care (€743.65), a positive net benefit was produced as women's marginal WTP for this model of care exceeded the marginal cost (€77.48). With similar median valuations, the results remained unchanged when these data were assumed (€56.35). The largest net benefit was produced by midwifery-led care, estimated at $€ 1538.71$ using mean WTP and $€ 1443.65$ using median WTP.

Table 5 presents the results of the 10,000 Monte Carlo simulations. Using WTP estimates from the full sample, we found similar results to the base case analysis, suggesting both models of care were cost-beneficial (The resulting interval parameter estimates are illustrated in ESM Table S4.). The average postnatal length of stay following care in a CLU was varied from 1.4 days at its minimum (€976.28) to 2.7 days at its maximum (€1905.05). Following a package of care in a MLU, the PSA varied the average postnatal length of stay from a minimum of 0.85 days (€586.61) to a maximum of 1.3 days (€887.25). At its

Table 4 Net-benefit results (base-case analysis)

\begin{tabular}{llllll} 
& $\begin{array}{l}\text { Marginal } \\
\text { cost }\end{array}$ & Marginal benefit (mean WTP) & $\begin{array}{l}\text { Marginal benefit (median } \\
\text { WTP) }\end{array}$ & Net benefit (mean WTP) & Net benefit (median WTP) \\
\hline CLU & $€ 743.65$ & $€ 821.13$ & $€ 800.00$ & $€ 77.48$ & $€ 56.35$ \\
MLU & $€-743.65$ & $€ 795.06$ & $€ 700.00$ & $€ 1538.71$ & $€ 1,443.65$ \\
\hline
\end{tabular}

$C L U$ consultant-led unit, $M L U$ midwifery-led unit, $W T P$ willingness to pay

Table 5 Net benefit results (probabilistic sensitivity analysis)

\begin{tabular}{llll}
\hline & Marginal cost $(95 \%$ CI $)$ & Marginal benefit $(95 \%$ CI $)$ & Net benefit (95 \% CI) \\
\hline Full sample & & & $€ 123.23(-376.58-621.42)$ \\
CLU & $€ 697.35(209.47-1,185.62)^{\mathrm{a}}$ & $€ 820.58(709.42-932.07)$ & $€ 1,491.22(989.35-1991.93)$ \\
MLU & $€-697.35(-1185.62 \text { to }-209.47)^{\mathrm{b}}$ & $€ 793.87(685.28-904.16)$ & \\
First-time mothers only & & $€ 887.94(737.01-1,036.44$ & $€ 1,50.14(-322.37-700.53)$ \\
CLU & $€ 697.81(209.76-1177.53)^{\mathrm{c}}$ & $€ 833.01(652.05-1,011.44)$ & $(1003.88-2055.09)$ \\
MLU & $€-697.81(-209.76 \text { to }-1177.53)^{\mathrm{d}}$ &
\end{tabular}

$C L U$ consultant-led unit, $M L U$ midwifery-led unit

${ }^{\text {a }}$ Estimated mean cost of a package of care in a CLU is $€ 1760.58$

${ }^{\mathrm{b}}$ Estimated mean cost of a package of care in a MLU is $€ 1063.23$

${ }^{c}$ Estimated mean cost of a package of care in a CLU is $€ 1761.12$

${ }^{\mathrm{d}}$ Estimated mean cost of a package of care in a MLU is $€ 1063.32$ 
lowest, the estimated cost of a package of care in a CLU (€1296.30) was higher than the maximum cost of a package of care in a MLU (€1217.58), confirming that midwiferyled care consistently cost less than consultant-led care in Ireland. The benefit valuations varied, although there was no difference in women's WTP for care in a CLU [€820.58 (95\% CI 709.42-932.07)] or MLU [€793.87 (95\% CI 685.28-904.16)]. The net benefit results showed both models of care were cost-beneficial, although some uncertainty was observed in the expected net benefit of consultant-led care, which sometimes produced a negative net benefit [ $€ 123.23$ (95\% CI -376.58 to 621.42$)]$. Consistently, midwifery-led care reflected the most cost-beneficial alternative. Similar findings were observed when we limited the analysis to first-time mothers only, as these women were willing to pay more for both models of care (Table 5).

\section{Conclusions}

The primary objective of this analysis was to inform priority setting by explicitly ranking consultant- and midwifery-led care in Ireland in terms of their expected benefits and costs. This is the first study to estimate the net benefit of consultant- and midwifery-led care in Ireland, with the results arriving at a particularly useful juncture in Irish policy formulation. Consistently, midwifery-led care ranks as the best use of public resources and should be adopted for low-risk women ahead of consultant-led care, in the face of budget constraints. The net benefit produced by this model of care, using results obtained from the probabilistic analysis, is estimated at $€ 1491.22$ (95\% CI 989.35-1991.93). While consultant-led care is also costbeneficial for women who prefer this model of care, the net benefit is considerably smaller, calculated at $€ 123.23$ (95\% CI -376.58 to 621.42 ), with some uncertainty in the expected net benefit observed. When we limit the analysis to first-time mothers, for whom the perspective is truly ex ante, we find comparable results.

Whether midwifery-led care should be developed in Ireland largely depends on resource constraints. While both models of care are cost-beneficial and should be pursued, as per standard cost-benefit analysis decision rules, the decision to provide both services may be impacted by budget constraints. If only one alternative can be pursued, then the CBA suggests that midwifery-led care should be undertaken for all low-risk women (leaving consultant-led care for high-risk women) as the net benefit of this model of care is considerably higher than consultant-led care. However, pursuing only one alternative sharply contradicts a key objective of government policy, which aims to improve maternal choice at hospital level [9]. The decision then to expand midwifery-led care and restrict access to consultant-led care is complex and controversial. Ideally, both alternatives should be pursued.

To the best of our knowledge, this is the first study to provide an empirical application of the marginal approach within CBA, providing an important contribution to the CVM and CBA literature. The usefulness of the technique to provide an explicit ranking of alternatives is well demonstrated here. We assume the WTP data elicited using this approach are also valid as they do not exceed the price of a package of private care. As women availing of public care were invited to participate in this study, this group already revealed a preference for public care. If the WTP valuations exceeded the cost of private care, which costs approximately $€ 3,500$ (based on expert opinion), then the results of the ex ante WTP question would be questionable given respondents revealed preferences.

The cost estimates generated here represent the most upto-date information on costing in maternity care in Ireland. The cost of a package of care in a CLU following an uncomplicated pregnancy and childbirth is estimated at $€ 1,762.12$. For the same package of care in a MLU, the estimated cost is $€ 1,018.47$. The cost differential is $€ 743.65$ in favour of care in a MLU, which is not too dissimilar from recent findings by Kenny et al. [34]. These authors, using MidU [8] data, estimated the cost differential between both models of care on an intention-to-treat basis and found a cost saving in favour of care in a MLU in the region of $€ 182$, although the authors included costs arising from temporary and permanent transfers from the MLU to the CLU. We did not include these costs in our analysis as our CVM was not developed to capture women's WTP under conditions of risk and uncertainty. Communicating risk in a CVM is prone to bias as respondents' perception of risk is guided by heuristics [35]. Risk can be conveyed using probabilities or absolute frequencies, although the effect of either approach on WTP is unclear [35]. Further research is ongoing in this area [19].

We acknowledge the limitations of this research. The natural perspective in any CBA is that of society's, consistent with the underlying paradigm [11]. However, we assume a third-party payer perspective in this study. To explore broader costs and benefits, other relevant cost and benefit considerations would be required. A consideration of society's valuation of an obstetric doctor's time could perhaps be included on the cost side. On the benefit side, a consideration of the general population's WTP could be useful to capture societal WTP values. To capture all possible externalities, a combined sample of patient and general population values might also be more relevant within a broader perspective $[19,36]$. Ortega et al. [36] used these perspectives in a contingent valuation study where two different WTP questions were developed to fit 
both perspectives. However, the benefit estimates were not compared with cost estimates in a formal CBA.

A limitation of the contingent valuation exercise relates to sample size. We obtained a low response rate to the WTP question and were unable to make any inferences about those respondents that did not participate. Few protest responses were obtained; among those who protested against the WTP question, a reluctance to assign a monetary valuation to maternity care was universally cited by women because they believed maternity care should be provided free of charge. Due to small sample size, we were also unable to draw meaningful comparisons across protest responders and positive WTP responders. Fortunately, few protest responses were obtained, suggesting women largely felt comfortable answering the WTP question. While it is difficult to assess the validity of the WTP data, as consultant- and midwifery-led care are free in Ireland, we assume the data are valid as they do not exceed the cost of private maternity care.

Finally, the cost and benefit estimates compared in this analysis are hypothetically matched. We considered attributes that were important to women when choosing between alternative models of care, as demonstrated by Fawsitt et al. [22]. Inputs associated with labour duration, for example, which women may have little influence over, were not included in the CVM scenario description, but were estimated on the cost side to ensure an accurate representation of cost inputs were accounted for. This afforded us with the flexibility to depict the 'typical' scenario found in a CLU and MLU in the CVM using those features of care that were important to women. We acknowledge that maternity care is dynamic and it is difficult to represent a 'typical' scenario; waiting times at antenatal clinics may vary and women may not be seen by the same midwife at each visit, or during labour. Any change in these attributes/services is likely to affect women's WTP. Future research could explore women's WTP (or WTA compensation) for service configurations.

Consultant- and midwifery-led care are cost-beneficial and should be pursued in Ireland, depending on resource constraints. The marginal approach provides an explicit ranking of available alternatives and, when compared with relative costs in a formal CBA, provides important information on the most efficient allocation of scarce resources, consistent with welfare economics and priority setting. Further research is required to develop CBA and WTP methodologies for use in priority setting. To date, there are no formal guidelines on how to approach and design a contingent valuation study within healthcare and how WTP data can be formally incorporated into a CBA [19]. Within environmental economics, the National Oceanic Atmospheric Association (NOAA) published a set of guidelines on how to conduct CVM studies [37]. Similar guidelines are required within the health economics literature to advance the CVM and CBA methodologies to inform decision-making and guide priority setting.

Acknowledgements We thank the participants of the study for taking the time to share their preferences with us. We also thank Ms. Yvonne Freyne (Cork University Maternity Hospital), Ms. Rachel Conaty (the National Maternity Hospital, Dublin), Ms. Margaret Mulvany (Cavan General Hospital), Ms. Colette McCann (Our Lady of Lourdes Hospital, Drogheda), and Ms. Connie McDonagh (St. Luke's Hospital, Kilkenny) for facilitating the acquisition of patient contact details.

Author contributions The following authors contributed critical revision of the manuscript for intellectual content and approved its submission for publication: CGF, JB, AM, BMcE, JEL, RM and RAG. CGF, JB, AM, BMcE, JEL, RM and RAG conceived and designed the study. CGF, JB, AM and BMcE analysed the data. CGF, $\mathrm{JB}, \mathrm{AM}, \mathrm{BMcE}$, JEL and RAG wrote the paper.

\section{Compliance with ethical standards}

Funding This work was supported by the National Perinatal Epidemiology Centre, University College Cork, Ireland.

Conflicts of interest Christopher G. Fawsitt, Jane Bourke, Aileen Murphy, Brendan McElroy, Jennifer E. Lutomski, Rosemary Murphy, and Richard A. Greene declare they have no conflicts of interest.

Ethical approval Ethical approval for this study was granted by the Clinical Research Ethics Committee, Division of Obstetrics and Gynaecology in Cork University Maternity Hospital; the Health Service Executive (HSE) Mid-Western Regional Hospital Research Ethics Committee; the HSE South-Eastern Regional Hospital Research Ethics Committee; and the Research Ethics Committee in the National Maternity Hospital, Dublin. Participants provided written consent to participate in this study.

Open Access This article is distributed under the terms of the Creative Commons Attribution-NonCommercial 4.0 International License (http://creativecommons.org/licenses/by-nc/4.0/), which permits any noncommercial use, distribution, and reproduction in any medium, provided you give appropriate credit to the original author(s) and the source, provide a link to the Creative Commons license, and indicate if changes were made.

\section{References}

1. NICE. Intrapartum care for healthy women and babies. London: National Institute for Health and Clinical Excellence; 2014.

2. Begley C, et al. Comparison of midwife-led and consultant-led care of healthy women at low risk of childbirth complications in the Republic of Ireland: a randomised trial. BMC Pregnancy and Childbirth. 2011;11(1):85.

3. Hatem M, et al. Midwife-led versus other models of care for childbearing women. Cochrane Database Syst Rev. 2008;4:CD004667.

4. Rooks JP, Weatherby NL, Ernst EKM. The National Birth Centre Study. Part II. Intrapartum and immediate postpartum and neonatal care. J Nurse-Midwifery. 1992;37(5):310-30.

5. Waldenstrom $U$, et al. Team midwife care: maternal and infant outcomes. Aust N Z J Obstet Gynaecol. 2001;41(3):257-64.

6. Waldenstrom U, Nilsson CA, Windbladh B. A randomized controlled study of birth centre care versus standard maternity care: effects on women's health. Birth. 1997;24(1):17-26. 
7. Hundley V, Ryan M, Graham W. Assessing women's prefernces for intrapartum care. Birth. 2001;28(4):254-63.

8. MidU. An evaluation of midwifery-led care in the Health Service Executive North Eastern area. Dublin: Trinity College Dublin; 2009.

9. DOH. Creating a better future together: national maternity strategy 2016-2026. Dublin: Department of Health; 2016.

10. McGuire A. Theoretical concepts in the economic evaluation of healthcare. In: Drummond M, McGuire A, editors. Economic evaluation in health care: merging theory with practice. Oxford: Oxford University Press; 2001.

11. Mishan EJ. Cost benefit analysis. London: Macmillan Books; 1971.

12. Diener A, O'Brien B, Gafni A. Health care contingent valuation studies: a review and classification of the literature. Health Econ. 1998;7(4):313-26.

13. Carson R. Contingent valuation: a comprehensive bibliography and history. Cheltenham: Edward Elgar; 2011.

14. McIntosh E. Introduction. In: McIntosh E, et al., editors. Applied methods of cost-benefit analysis in health care. New York: Oxford University Press; 2010.

15. Hoevenagel R. A comparison of economic valuation methods. In: Pethig R, editor. Valuing the environment: methodological and measurement issues. Dordrecht: Kluwer Academic; 1994. pp. 251-270.

16. Haefeli $\mathrm{M}$ et al. A cost-benefit analysis using contingent valuation techniques: a feasibility study in spinal surgery. Value in Health (Wiley-Blackwell). 2008;11(4):575-588.

17. Shackley P, Donaldson C. Willingness to pay for publicly-financed healthcare: how should we use the numbers? Appl Econ. 2000;32(15):2015-21.

18. Brazier J, et al. Should patients have a greater role in valuing health states? Appl Health Econ Health Policy. 2005;4(4):201-8.

19. Frew EJ. Benefit assessment for cost-benefit analysis studies in healthcare using contingent valuation methods. In: McIntosh E, et al., editors. Applied methods of cost-benefit analysis in health care. New York: Oxford University Press; 2010.

20. Donaldson C, et al. Assessing community values in healthcare: is the 'Willingness to pay' method feasible? Health Care Analysis. 1997;5(1):7-29.

21. Frew EJ. Benefit assessment for cost-benefit analysis studies in healthcare: a guide to carrying out a stated preference willingness to pay survey in healthcare. In: McIntosh E, et al., editors. Applied methods of cost-benefit analysis in health care. New York: Oxfor University Press; 2010.
22. Fawsitt CG, et al. What women want: exploring pregnant women's preferences for alternative models of maternity care. Health policy. 2017;121(1):66-74.

23. Higgins JR. The establishment of hospital groups as a transition to independent hospital trusts: Department of Health and Children, Editor. Dublin; 2013.

24. Brouwer W, Rutten F, Koopmanschap. Costing in economic evaluations. In: Drummond M, McGuire A, editors. Economic evaluation in health care: merging theory with practice. Oxford: Oxford University Press; 2001.

25. HPO. Activity in acute public hospitals in Ireland. Dublin: Healthcare Pricing Office; 2014.

26. Schroeder L et al. Birthplace cost-effectiveness analysis of planned place of birth: individual level analysis. In: Birthplace in England research programme. Final report part 5. National Institue for Health Research; 2011.

27. [Unamed Authors]. Consolidated salary scales 2016. Department of Health; 2016.

28. HIQA. Guidelines for the economic evaluation of health technologies in Ireland. Dublin: The Health Information and Quality Authority; 2014.

29. HSE. Ready Reckoner of acute hospital inpatient and daycase activity and costs (summarised by DRGs) relating to 2011. National Casemix Programme: Dublin; 2013.

30. Pearce D, Atkinson G, Mourato S. Cost benefit analysis and the environment. Recent developments. Organisation for Economic Co-operation and Development; 2006.

31. Microsoft. Microsoft Excel. Redmond: Microsoft Corporation; 2010.

32. StataCorps. Stata Statistical Software: Release 12. College Station: Stata Press; 2012.

33. Chilton S, et al. Valuation of health benefits associated with reductions in air pollution. Final report. London: Department of Environment, Food, and Rural Affairs; 2004.

34. Kenny C, et al. A cost-comparison of midwife-led compared with consultant-led maternity care in Ireland (the MidU study). Midwifery. 2015; 31(11):1032-8.

35. Lloyd AJ. Threats to the estimation of benefit: are preference elicitation methods accurate? Health Econ. 2003;12(5):393-402.

36. Ortega A, Dranitsaris G, Puodziunas AL. What are cancer patients willing to pay for prophylactic epoetin alfa? A costbenefit analysis. Cancer. 1998;83(12):2588-96.

37. Arrow KJ, et al. Report of the NOAA panel on contingent valuation. Federal Register, Washington DC; 1993. 